\title{
Phytochemical Screening and Antioxidant Activity Test of Red Onion (Allium ascolinicum L.) Extract Variety of Palu Valley
}

\author{
${ }^{*}$ Rimah Juwita, Daud K. Walanda \& Supriadi \\ Pendidikan Kimia/FKIP - Universitas Tadulako, Palu - Indonesia 94119 \\ Received 03 March 2020, Revised 02 April 2020, Accepted 04 May 2020 \\ doi: 10.22487/j24775185.2020.v9.i2.pp63-69
}

\begin{abstract}
The red onion of Palu valley variety is a plant that is widely found in Palu area and regarded as a leading commodity in Central Sulawesi. The purpose of this study was to examine the secondary metabolite compounds contained in red onion (Allium ascolinicum L.) of Palu valley variety and its antioxidant activity. Antioxidant activity test in this study used DPPH (1,1-Diphenyl-2-Pikrilhidrazil) as a source of free radical, and vitamin $C$ as the comparison. The antioxidant activity of red onion extract was analyzed using a UV-Vis spectrophotometer. The red onion tuber powder was extracted by maceration using ethanol solvent. Qualitative test of onion powder showed positive results on alkaloids, flavonoids, and tannin compounds. The samples and vitamin $C$ were tested for antioxidant activity in various extract concentrations of 10,30,50,70, and $90 \mathrm{ppm}$. The results showed that red onion extract of Palu valley variety presented an $I C_{50}$ value of $38.548 \mathrm{ppm}$, and vitamin $C$ presented an $I C_{50}$ value of $22.646 \mathrm{ppm}$. Based on these values, the red onion (Allium ascolinicum L.) extract is categorized as a very strong class of antioxidant which can be used as a source of natural antioxidant.
\end{abstract}

Keywords: Antioxidants, qualitative test, red onion of Palu valley variety, DPPH, UV-Vis spectrophotometer, IC50

\section{Pendahuluan}

Indonesia memiliki kekayaan hayati yang sangat besar. Salah satunya adalah tumbuhan yang telah menjadi sumber potensial untuk agen terapeutik selama bertahun-tahun dan telah banyak berkembang menjadi obat-obat moderen. Umumnya di dalam tanaman tertentu terdapat senyawa fitokimia seperti fenolik, flavonoid, turunan kumarin dan lainnya. Senyawa ini diketahui dapat menangkal stres oksidatif dalam tubuh manusia dengan cara membantu mempertahankan keseimbangan antara oksidan (radikal bebas) dan antioksidan (Febrinda, dkk., 2013).

Salah satu tanaman yang berpotensi sebagai antioksidan alami adalah bawang merah. Hal ini karena di dalam bawang merah mengandung senyawa kimia yang dapat bertindak sebagai antioksidan, salah satunya adalah flavonoid (Soebagio, dkk., 2007). Bawang merah memiliki banyak kegunaan bagi manusia, terutama sebagai bahan penyedap makanan dan dapat digunakan sebagai obat tradisional. Bawang merah kaya akan kandungan flavonglikosida, kuersetin, saponin, dan vitamin (Savitri, 2008).

Telah dilakukan penelitian tentang antioksidan pada berbagai jenis bawang, salah satunya adalah penelitian yang dilakukan oleh (Febrinda, dkk., 2013) tentang umbi bawang dayak yang menunjukkan bahwa di dalamnya terkandung senyawa fitokimia seperti alkaloid, tanin, fenolik, dan flavonoid. Semua jenis senyawa tersebut diketahui memiliki aktivitas sebagai antioksidan. Selain itu, penelitian (Sharon, dkk., 2013) menunjukkan bahwa ekstrak etanol bawang hutan dapat diformulasi menjadi sediaan krim yang memiliki potensi sebagai antioksidan.

Ada berbagai jenis bawang yang dibudidayakan oleh petani Indonesia. Salah satunya di area pertanian Lembah Palu (Sulawesi Tengah) yang beriklim kering terdapat jenis bawang merah yang beradaptasi dan dapat tumbuh serta berproduksi dengan baik (Ete \& Alam, 2009). Menurut Berita Resmi PVT (2015), jenis bawang merah ini dikenal dengan nama bawang merah varietas Lembah Palu yang berpotensi sebagai antioksidan sehingga bermanfaat dalam menangkal radikal bebas.

Radikal bebas merupakan molekul yang berbahaya karena sangat reaktif mencari pasangan elektronnya untuk mencapai kestabilan sedangkan antioksidan dalam pengertian kimia merupakan senyawa pemberi elektron. Antioksidan bekerja dengan cara mendonorkan satu elektronnya

${ }^{*}$ Correspondence

Rimah Juwita

e-mail: rimjut@gmail.com

(c) 2020 the Author(s) retain the copyright of this article. This article is published under the terms of the Creative Commons Attribution License 4.0, which permits unrestricted non-commercial use, distribution, and reproduction in any medium, provided the original work is properly cited. 
kepada senyawa yang bersifat oksidan (radikal bebas) sehingga aktivitas senyawa tersebut bisa terhambat (Winarsih, 2007). Akan tetapi, tubuh manusia tidak mempunyai cadangan antioksidan yang berlebih, sehingga apabila terjadi paparan radikal berlebih maka tubuh memerlukan asupan antioksidan dari luar, yaitu dengan cara mengkonsumsi antioksidan alami (Rahayu, dkk., 2015). Antioksidan alami banyak ditemukan pada tanaman seperti buah, sayuran, bahkan rempahrempah yang mempunyai manfaat bagi kesehatan.

Tulisan ini dimaksudkan untuk mendeskripsikan terkait kandungan yang terdapat pada bawang merah varietas Lembah Palu yang dapat menghambat aktivitas radikal bebas dan kemampuannya sebagai bahan antioksidan alami.

\section{Metode}

Peralatan yang digunakan yaitu Spektrofotometer UV-Vis, rotary vacuum evaporator, neraca analitik, penangas air, shaker, blender, ayakan 60 mesh, dan peralatan gelas yang umum digunakan dilaboratorium. Bahan-bahan yang digunakan yaitu umbi bawang merah varietas Lembah Palu, Etanol 96\% (Merck), Reagen Dragendorff (Merck), serbuk Mg (Merck), $\mathrm{HCl} 2 \mathrm{~N}$ (Merck), $\mathrm{NaOH} 5 \%$ (Merck), $\mathrm{FeCl}_{3} 1 \%$ (Merck), $\mathrm{HCl}$ pekat, $\mathrm{H}_{2} \mathrm{SO}_{4}$ pekat (Merck), asam asetat glasial, Aquades, Vitamin C, DPPH (1,1difenil-2-pikrilhidrazil).

Pembuatan ekstrak bawang merah varietas Lembah Palu dilakukan dengan cara preparasi sampel terlebih dahulu sehingga sampel menjadi serbuk, kemudian mengekstraksi sampel secara maserasi dengan cara mencampurkan $20 \mathrm{~g}$ serbuk bawang merah varietas Lembah Palu dengan 200 $\mathrm{mL}$ etanol $96 \%$. Setelah itu didiamkan selama $2 \mathrm{x}$ 24 jam. Kemudian menyaring campuran tersebut dan menampung filtrat hasil penyaringan. Residu yang diperoleh dimaserasi kembali selama 2 x 24 jam lalu disaring. Filtrat hasil maserasi pertama dan kedua digabung untuk selanjutnya dipekatkan dengan rotary vacuum evaporator hingga diperoleh ekstrak kental.

\section{Uji Pendahuluan}

\section{Uji Alkaloid}

$0.5 \mathrm{~g}$ sampel ditambahkan $1 \mathrm{~mL} \mathrm{HCl} 2 \mathrm{~N}$ dan $9 \mathrm{~mL}$ aquades. Larutan dipanaskan selama 2 menit lalu didinginkan dan disaring. Filtrat ditambahkan 4-5 tetes Reagen Dragendorff, jika terbentuk endapan merah bata atau jingga maka sampel positif mengandung alkaloid (Marjoni, 2016).

\section{Uji Flavonoid}

$0.5 \mathrm{~g}$ sampel ditambahkan $5 \mathrm{~mL}$ etanol lalu dipanaskan selama 5 menit. kemudian ditambah beberapa tetes $\mathrm{HCl}$ pekat dan $0.1 \mathrm{~g}$ serbuk $\mathrm{Mg}$. Jika terbentuk warna kuning, jingga, atau merah maka sampel positif mengandung flavonoid (Ayun \& Laily, 2015).

\section{Uji Saponin}

$0.5 \mathrm{~g}$ sampel ditambahkan $10 \mathrm{~mL}$ aquades dan dididihkan 5 menit lalu disaring. Filtrat dikocok selama 10 menit dan ditambah $1 \mathrm{~mL} \mathrm{HCl}$ $2 \mathrm{~N}$. Jika terbentuk buih yang stabil maka sampel positif mengandung saponin (Nugrahani, dkk., 2016).

\section{Uji Tanin}

0,5 g sampel ditambahkan $5 \mathrm{~mL}$ etanol dan disaring. Filtrat sebanyak $2 \mathrm{~mL}$ ditambahkan 1 $\mathrm{mL} \mathrm{FeCl}_{3}$ 1\%. Jika terbentuk warna hijau kehitaman atau biru kehitaman maka sampel positif mengandung tanin (Ayun \& Laily, 2015).

\section{Uji Triterpenoid dan Steroid}

$0.5 \mathrm{~g}$ sampel dilarutan dalam asam asetat glasial dan ditambahkan $1 \mathrm{~mL} \mathrm{H}_{2} \mathrm{SO}_{4}$ pekat. Jika terbentuk warna biru atau hijau maka sampel mengandung steroid sedangkan jika terbentuk warna merah atau ungu maka sampel positif mengandung triterpenoid (Dapas, dkk., 2014).

\section{Uji Kuinon}

$0.5 \mathrm{~g}$ sampel ditambahkan $5 \mathrm{~mL}$ etanol lalu dipanaskan diatas penangas air kemudian disaring. Filtrat ditambahkan 4-5 tetes $\mathrm{NaOH} \mathrm{5 \% .}$ Jika terbentuk warna merah maka sampel positif mengandung kuinon (Noer \& Pratiwi, 2016).

\section{Uji Aktivitas Antioksidan}

\section{Pembuatan Larutan DPPH 100 ppm}

$10 \mathrm{mg}$ serbuk DPPH dimasukkan dalam labu ukur $100 \mathrm{~mL}$, kemudian dicukupkan volumenya dengan etanol 96\% sampai tanda batas (Nur, dkk., 2016).

\section{Pembuatan Larutan Blanko DPPH 50 ppm}

$25 \mathrm{~mL}$ larutan induk DPPH $100 \mathrm{ppm}$ dimasukkan kedalam labu ukur $50 \mathrm{~mL}$ lalu dicukupkan volumenya dengan etanol 96\% sampai tanda batas (Sharon, dkk., 2013).

\section{Pembuatan Larutan Induk Ekstrak Sampel 500 ppm}

$25 \mathrm{mg}$ ekstrak etanol bawang merah varietas Lembah Palu dimasukkan dalam labu ukur $50 \mathrm{~mL}$ lalu volumenya dicukupkan dengan etanol 96\% sampai tanda batas (Nur, dkk., 2016).

\section{Pembuatan Seri Konsentrasi Larutan Uji Ekstrak Sampel (10, 30, 50, 70, 90) ppm}

Sebanyak 1, 3, 5, 7, dan $9 \mathrm{~mL}$ larutan induk ekstrak sampel $500 \mathrm{ppm}$ dimasukkan ke dalam labu ukur $50 \mathrm{~mL}$ yang berbeda dan volumenya dicukupkan dengan etanol 96\% sampai tanda batas (Karim, dkk., 2015).

\section{Pembuatan Larutan Pembanding Vitamin C 500 ppm}

$25 \mathrm{mg}$ vitamin $\mathrm{C}$ dimasukkan dalam labu ukur $50 \mathrm{~mL}$ lalu volumenya dicukupkan dengan etanol 96\% sampai tanda batas (Nur, dkk., 2016). 
Pembuatan Seri Konsentrasi Vitamin C (10, 30 , 50, 70, 90) ppm

Sebanyak 1, 3, 5, 7, dan $9 \mathrm{~mL}$ larutan pembanding vitamin C 500 ppm dimasukkan ke dalam labu ukur $50 \mathrm{~mL}$ yang berbeda dan volumenya dicukupkan dengan etanol 96\% sampai tanda batas (Karim, dkk., 2015).

\section{Pengukuran Serapan Blanko}

Pengukuran dilakukan dengan cara memipet $4 \mathrm{~mL}$ larutan DPPH 50 ppm tanpa penambahan larutan uji kemudian dihomogenkan dan didiamkan selama 30 menit. Selanjutnya diukur absorbansinya dengan spektrofotometer UV-Vis pada panjang gelombang $517 \mathrm{~nm}$. Semua pengerjaan dilakukan pada ruang yang terhindar dari cahaya matahari (Molyneux, 2004).

\section{Pengukuran Serapan Larutan Uji dan Larutan Pembanding}

Masing-masing seri konsentrasi larutan uji dan larutan pembanding diambil sebanyak $2 \mathrm{~mL}$ dan ditambahkan dengan 2 mL DPPH 50 ppm lalu dihomogenkan kemudian didiamkan selama 30 menit. Selanjutnya diukur absorbansinya dengan spektrofotometer UV-Vis pada panjang gelombang $517 \mathrm{~nm}$. Pengukuran dilakukan sebanyak 3 kali (Molyneux, 2004).

\section{Penentuan Persen Inhibisi}

Aktivitas penangkal radikal bebas diekspresikan sebagai persen inhibisi yang dapat dihitung dengan rumus yang diterapkan oleh (Ghosal \& Mandal, 2012) sebagai berikut:

$$
\% \text { Inhibisi }=\frac{(\text { abs kontrol }- \text { abs bahan uji) }}{\text { abs kontrol }} \times 100 \%
$$

\section{Pengukuran Aktivitas Antioksidan}

Aktivitas antioksidan ditentukan dengan nilai $\mathrm{IC}_{50}$ dari senyawa antioksidan. Nilai $\mathrm{IC}_{50}$ diperoleh dari beberapa tahapan yaitu mengitung nilai log konsentrasi dan nilai probit dari sampel.

\section{Hasil dan Pembahasan}

\section{Uji Pendahuluan}

Ekstrak etanol bawang merah varietas Lembah Palu yang telah dipekatkan kemudian dilakukan pengujian fitokimia. Pengujian ini meliputi uji senyawa alkaloid, flavonoid, tanin, saponin, kuinon, triterpenoid dan steroid. Tujuan dilakukannya pengujian ini adalah untuk mengetahui senyawa metabolit sekunder yang terkandung dalam bawang merah varietas Lembah Palu. Metabolit ini diharapkan dapat berfungsi sebagai antioksidan. Hasil yang diperoleh yaitu sampel mengandung senyawa flavonoid, alkaloid, dan tanin, sedangkan untuk saponin, kuinon, triterpenoid dan steroid diperoleh hasil negatif.

Hasil positif flavonoid ditandai dengan terbentuknya warna kuning kemerahan, setelah ditambahkan serbuk $\mathrm{Mg}$ dan $\mathrm{HCl}$. Penambahan serbuk $\mathrm{Mg}$ dan $\mathrm{HCl}$ berfungsi untuk mereduksi inti benzopiron yang terdapat dalam struktur flavonoid sehingga terbentuk garam flavilium berwarna merah atau jingga (Robinson, 1995).

Adanya alkaloid pada sampel dilihat dari hasil positif pada uji fitokimia dengan terbentuknya endapan merah bata setelah ditambahkan reagen Dragendorff. Endapan yang terbentuk merupakan kalium-alkaloid, karena senyawa alkaloid mengandung atom nitrogen yang mempunyai pasangan elektron bebas sehingga dapat digunakan untuk membentuk ikatan kovalen koordinat dengan ion logam. Nitrogen pada alkaloid akan bereaksi dengan ion logam $\mathrm{K}^{+}$dari kalium tetraiodomerkurat(II) membentuk kompleks kalium-alkaloid yang mengendap (Nugrahani, dkk., 2016).

Adanya tanin pada sampel dilihat dari terbentuknya warna hijau kehitaman setelah ditambahkan pereaksi $\mathrm{FeCl}_{3}$. Penggunaan pereaksi ini bertujuan untuk mengetahui apakah sampel mengandung gugus fenol atau tidak. Terbentuknya warna hijau kehitaman pada sampel ini dikarenakan tanin akan membentuk senyawa kompleks dengan ion $\mathrm{Fe}^{3+}$.

\section{Uji Aktivitas Antioksidan}

Uji aktivitas antioksidan terhadap ekstrak bawang merah varietas Lembah Palu dilakukan menggunakan DPPH (1,1-difenil-2pikrilhidrazil). Metode uji menggunakan DPPH merupakan salah satu metode uji kuantitatif untuk menentukan daya aktivitas bawang merah varietas Lembah Palu sebagai antioksidan (Rizkayanti, dkk., 2017). Penggunaan metode uji menggunakan DPPH ini dipilih karena merupakan metode yang sederhana, mudah, cepat dan peka serta hanya memerlukan sedikit sampel (Molyneux, 2004).

Pengujian aktivitas antioksidan dilakukan pada panjang gelombang $517 \mathrm{~nm}$. Hal ini dikarenakan $517 \mathrm{~nm}$ merupakan panjang gelombang maksimum dari DPPH (Tonahi, dkk., 2014). Pengukuran aktivitas antioksidan didasarkan pada prinsip pengurangan intensitas warna ungu DPPH yang sebanding dengan pengurangan konsentrasi larutan DPPH. Peredaman tersebut dihasilkan oleh bereaksinya molekul DPPH dengan atom hidrogen yang dilepaskan satu molekul komponen sampel sehingga terbentuk senyawa DPPH-H dan menyebabkan terjadinya peluruhan warna DPPH dari ungu ke kuning (Zuhra, dkk., 2008).

Hasil pengamatan dari proses pengukuran serapan absorbansi ekstrak bawang merah varietas Lembah Palu disajikan dalam Gambar 1. Berdasarkan data pada gambar tersebut, dapat dilihat bahwa nilai absorbansi DPPH semakin berkurang seiring dengan bertambahnya konsentrasi ekstrak sampel. Hal ini dapat terjadi karena adanya reduksi radikal DPPH oleh antioksidan, dimana semakin tinggi konsentrasi ekstrak sampel maka partikel-partikel senyawa 
antioksidan yang terkandung akan semakin banyak sehingga semakin besar pula aktivitas antioksidannya dan menyebabkan absorbansi DPPH semakin berkurang (Talapessy, dkk., 2013). Akan tetapi, pada konsentrasi 90 ppm terjadi penurunan absorbansi yang drastis sehingga grafik yang diperoleh tidak sesuai dengan hukum "Lambert-Beer", dimana grafik konsentrasi dengan absorbansi akan membentuk suatu garis lurus. Hal ini dikarenakan konsentrasi optimum yang sesuai dengan deret absorbansi ideal yaitu pada konsentrasi $70 \mathrm{ppm}$, diatas konsentrasi tersebut nilai absorbansinya sudah menurun cukup jauh dari rentang absorbansi yang ideal (Yoga, 2015).

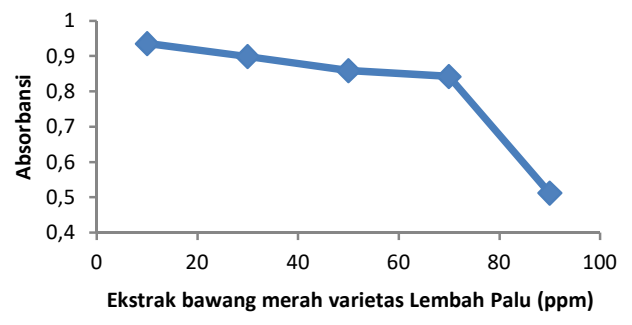

Gambar 1. Nilai absorbansi DPPH terhadap ekstrak bawang merah varietas Lembah Palu

Berbeda dengan ekstrak sampel, grafik absorbansi yang diperoleh vitamin $\mathrm{C}$ pada Gambar 2 sesuai dengan hukum "Lambert-Beer" dimana suatu grafik hubungan antara konsentrasi dengan absorbansi akan membentuk suatu garis lurus. Selain itu, Gambar 2 menunjukkan bahwa semakin besar konsentrasi vitamin $\mathrm{C}$ maka semakin kuat vitamin $\mathrm{C}$ dalam meredam radikal bebas DPPH yang ditandai dengan terjadinya perubahan warna larutan DPPH menjadi kuning seiring bertambahnya konsentrasi.

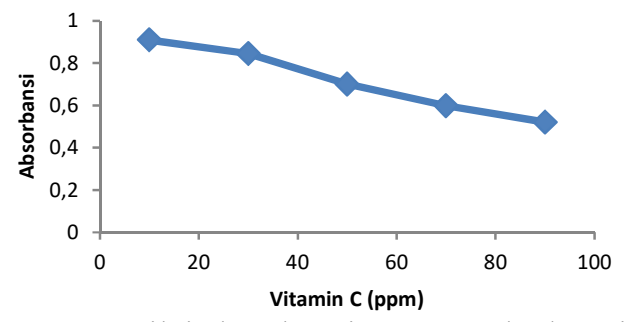

Gambar 2. Nilai absorbansi DPPH terhadap vitamin C

Berdasarkan nilai absorbansi ekstrak bawang merah varietas Lembah Palu maka diperoleh pula aktivitas antioksidan berdasarkan persentase penghambatannya yang dapat diilustrasikan pada Gambar 3.

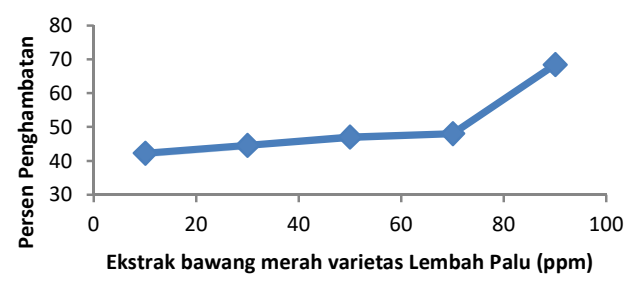

Gambar 3. Aktivitas antioksidan dari ekstrak bawang merah varietas Lembah Palu

Gambar tersebut menunjukkan bahwa semakin besar konsentrasi ekstrak sampel maka semakin besar pula persentase aktivitas antioksidan dalam menghambat radikal bebas DPPH. Persen penghambatan radikal tertinggi yaitu pada konsentrasi $90 \mathrm{ppm}$ dengan persen penghambat sebesar $68,43 \%$ sedangkan yang terendah yaitu pada konsentrasi 10 ppm dengan persen penghambat sebesar $42.29 \%$.

Berdasarkan hasil pengukuran absorbansi terhadap vitamin $\mathrm{C}$ sebagai pembanding, maka diperoleh pula persen penghambatannya seperti pada Gambar 4. 


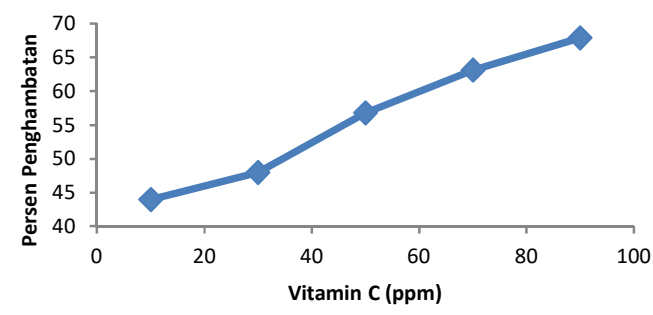

Gambar 4. Aktivitas antioksidan dari vitamin C

Sama seperti pada ekstrak sampel, persen penghambatan tertinggi vitamin $\mathrm{C}$ ditunjukkan pada konsentrasi $90 \mathrm{ppm}$ dengan nilai sebesar $67.87 \%$ dan terendah pada konsentrasi $10 \mathrm{ppm}$ dengan nilai sebesar $43.95 \%$.

Hasil persen penghambatan yang diperoleh antara ekstrak bawang merah varietas Lembah Palu dan vitamin $\mathrm{C}$ pada penelitian ini tidaklah jauh berbeda. Bahkan pada konsentrasi 90 ppm, persen penghambatan ekstrak bawang merah varietas Lembah Palu lebih tinggi dari vitamin C. Hal ini membuktikan bahwa ekstrak bawang merah varietas Lembah Palu memiliki kemampuan sebagai antioksidan yang hampir sama dengan vitamin $\mathrm{C}$.

Perbandingan persentase aktivitas antioksidan antara ekstrak bawang merah dan vitamin C dapat dilihat pada Gambar 5.

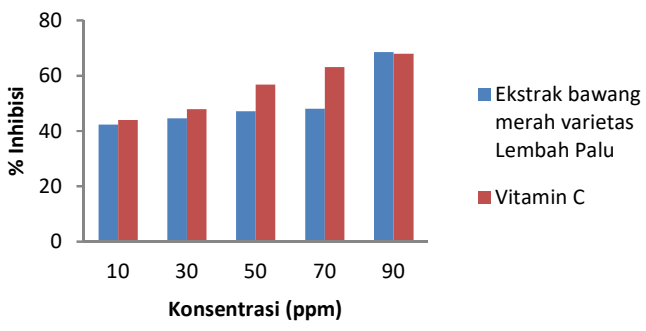

Gambar 5. Perbandingan persen penghambatan ekstrak sampel dan vitamin C

Adanya aktivitas antioksidan pada sampel dikarenakan adanya kandungan senyawa aktif seperti flavonoid, alkaloid, dan tanin yang menjadi sumber antioksidan. Senyawa flavonoid dan tanin menjadi sumber antioksidan yang sangat kuat disebabkan karena senyawa ini merupakan golongan polifenol yang memiliki banyak gugus hidroksil seperti pada vitamin C. Atom hidrogen dari gugus hidroksil ini dapat terprotonasi pada senyawa radikal sehingga senyawa tersebut dapat terstabilkan.

\section{Perhitungan Nilai IC So $_{50}$}

Penelitian ini menggunakan parameter $\mathrm{IC}_{50}$ untuk menginterpretasikan hasil pengujian aktivitas antioksidannya dengan menggunakan DPPH. $\mathrm{IC}_{50}$ merupakan substrat atau sampel yang akan menyebabkan reduksi terhadap aktivitas DPPH sebesar 50\% (Molyneux, 2004). Semakin kecil nilai $\mathrm{IC}_{50}$ berarti semakin tinggi aktivitas antioksidannya.

Nilai $\mathrm{IC}_{50}$ diperoleh dari nilai $\mathrm{x}$ pada persamaan regresi linear dengan mengganti nilai $\mathrm{y}=5$ (probit dari 50\%), kemudian nilai $\mathrm{x}$ yang diperoleh tersebut dikonversi ke bentuk antilog sehingga diperoleh nilai $\mathrm{IC}_{50}$ dalam konsentrasi ppm (Pratiwi, dkk., 2014). Hubungan log konsentrasi dan harga probit ekstrak bawang merah varietas Lembah Palu dan vitamin C dapat dilihat pada Gambar 6 dan 7.

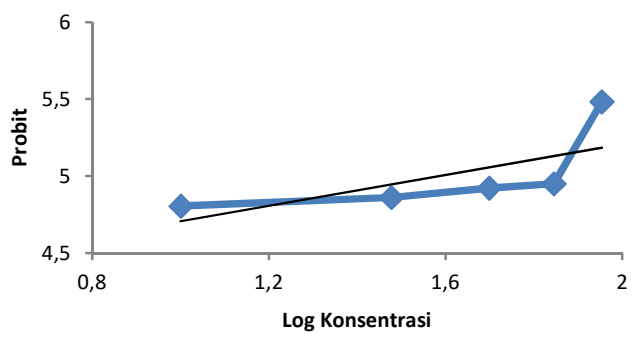

Gambar 6. Hubungan log konsentrasi dan probit ekstrak bawang merah varietas Lembah Palu 


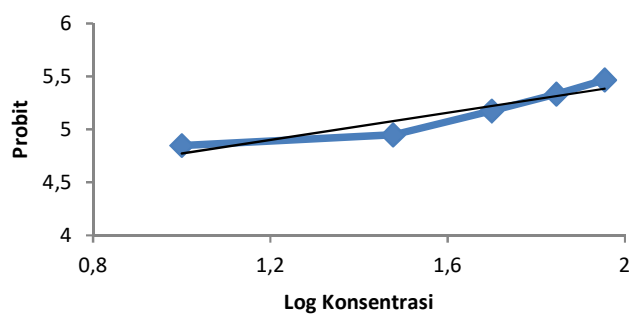

Gambar 7. Hubungan log konsentrasi dan probit Vitamin C

Berdasarkan Gambar 6 dan 7 diperoleh persamaan regresi linear $y=0.4995 x+4.2078$ untuk ekstrak sampel bawang merah varietas Lembah Palu, dan untuk vitamin C (pembanding) yaitu $\mathrm{y}=0.6406 \mathrm{x}+4.1322$. Selain itu, dari Gambar 6 dan 7 juga diperoleh nilai $r$ untuk ekstrak sampel dan vitamin $\mathrm{C}$ berturut-turut yaitu 0.476 dan 0.8804 . Dari hasil nilai r yang diperoleh maka dapat dikatakan bahwa data probit vitamin $\mathrm{C}$ lebih baik dari ekstrak bawang merah varietas Lembah Palu.

Adapun nilai $\mathrm{IC}_{50}$ yang diperoleh pada perhitungan akhir yaitu untuk ekstrak sampel adalah $38.548 \mathrm{ppm}$, sedangkan untuk vitamin C diperoleh nilai sebesar $22.646 \mathrm{ppm}$. Berdasarkan nilai $\mathrm{IC}_{50}$ tersebut, maka dapat disimpulkan bahwa ekstrak bawang merah varietas Lembah Palu tergolong antioksidan yang sangat kuat. Hal ini dikarenakan nilai $\mathrm{IC}_{50}$ yang diperoleh berada di bawah 50 ppm.

Berdasarkan literatur, diketahui bahwa aktivitas antioksidan menggunakan DPPH dapat digolongkan menurut nilai $\mathrm{IC}_{50}$. Antioksidan sangat kuat jika nilai $\mathrm{IC}_{50}$ kurang dari $50 \mathrm{ppm}$, kuat jika $\mathrm{IC}_{50}$ bernilai 50-100 ppm, sedang jika $\mathrm{IC}_{50}$ bernilai 100-150 ppm, dan lemah jika $\mathrm{IC}_{50}$ bernilai lebih dari 150 ppm (Molyneux, 2004).

\section{Kesimpulan}

Bawang merah varietas Lembah Palu terkandung senyawa flavonoid, alkaloid, dan tanin. Selain itu, ekstrak bawang merah varietas Lembah Palu memiliki nilai $\mathrm{IC}_{50}$ sebesar 38.548 ppm dan termasuk golongan antioksidan sangat kuat sehingga bawang ini dapat dijadikan sebagai antioksidan alami.

\section{Ucapan Terima Kasih}

Penulis mengucapkan terima kasih kepada laboran Laboratorium Kimia Fakultas Keguruan dan Ilmu Pendidikan Universitas Tadulako yang banyak membantu penulis dalam menyelesaikan penelitian ini.

\section{Referensi}

Ayun, Q., \& Laily, A. N. (2015). Analisis fitokimia daun pepaya (carica papaya 1.) di balai penelitian tanaman aneka kacang dan umbi kendalpayak Malang. Prosiding
Pemanfaatan Sumber Daya Alam 2015. Malang: Prosiding KPSDA.

Berita Resmi PVT. (2015). Pendaftaran varietas lokal. Jakarta: PVTPP.

Dapas, C. C., Koleangan, H. S. J., \& Sangi, M. (2014). Analisis senyawa metabolit sekunder dan uji toksisitas ekstrak batang bawang laut (proiphys amboinensis (1.) herb.). Jurnal MIPA Unsrat Online, 3(2), 144-148.

Ete, A., \& Alam, N. (2009). Karakteristik mutu bawang goreng palu sebelum penyimpanan. Jurnal Agroland, 16(4), 273-280.

Febrinda, A. E., Astawan, M., Wresdiyati, T., \& Yuliana, D. (2013). Kapasitas antioksidan dan inhibitor alfa glukosidase ekstrak umbi bawang dayak. Jurnal Teknologi dan Industri Pangan, 24(2), 161-167.

Ghosal, M., \& Mandal, P. (2012). Phytochemical screening and antioxidant activities of two selected 'bihi' fruit used as vegetables in darjeeling himalaya. International Journal of Pharmacy and Phamaceutical Science, 4(2), 567-574.

Karim, K., Jura, M. R., \& Sabang, S. M. (2015). Uji aktivitas antioksidan ekstrak daun patikan kebo (euphorbia hirta 1.). Jurnal Akademika Kimia, 4(2), 56-53.

Marjoni, R. (2016). Dasar-dasar fitokimia farmasi. Jakarta: Trans Info Media.

Molyneux, P. (2004). The use of the stable free radical diphenylpicryl-hydrazyl (DPPH) for estimating antioxidant activity. Songklanakarin Journal Science Technology, 26(2), 211-219.

Nugrahani, R., Andayani, Y., \& Hakim, A. (2016). Skrining fitokimia dari ekstrak buah buncis (phaseolus vulgaris 1.) dalam sediaan serbuk. Jurnal Penelitian Pendidikan IPA, 2(1), 96-103.

Nur, K., Diah, A. W. M., \& Nuryanti, S. (2016). Uji aktivitas ekstrak daun palado (agare angustifolia) sebagai antioksidan. Jurnal Akademika Kimia, 5(2), 73-78.

Noer, S., \& Pratiwi, R. D. (2016). Uji kualitatif fitokimia daun ruta angustifolia. Faktor Exacta, 9(3), 200-206.

Pratiwi, R. D., Bintang, M., \& Simanjuntak, P. (2014). Lelutung tokak (tabernaemontana macrocarpa jack.) sebagai sumber zat bioaktif antioksidan dan antikanker. Jurnal Ilmu Kefarmasian Indonesia, 12(2), 267-272. 
Rahayu, S., Kurniasih, N., \& Amalia, V. (2015). Ekstraksi dan identifikasi senyawa flavonoid dari limbah kulit bawang merah sebagai antioksidan alami. Al Kimiya, 2(1), 1-8.

Rizkayanti, Diah, A. W. M., \& Jura, M. R. (2017). Uji aktivitas antioksidan ekstrak air dan ekstrak etanol daun kelor (moringa oleifera lam). Jurnal Akademika Kimia, 6(2), 125-131.

Robinson, T. (1995). Kandungan organik tumbuhan tingkat tinggi. Bandung: ITB.

Savitri, E. S. (2008). Rahasia tumbuhan berkhasiat obat persfektif islam. Malang: UIN Malang.

Sharon, N., Anam, S., \& Yuliet. (2013). Formulasi krim antioksida ekstrak etanol bawang hutan (eleutherine palmifolia 1. merr). Journal of Science and Technology, 2(3), 111-122.

Soebagio, B., Rusdiana, T., \& Khairudin. (2007). Pembuatan gel dengan aquepec HV-505 dari ekstrak umbi bawang merah (allium cepa 1.) sebagai antioksidan. Seminar Penelitian Dosen Fakultas Farmasi Universitas Padjadjaran. Diakses https://adoc.pub/queue/pembuatan-gel- dengan-aqupec-hv-505-dari-ekstrak-umbibawang-.html.

Talapessy, S., Suryanto, E., \& Yudistira, A. (2013). Uji aktivitas antioksidan dari ampas hasil pengolahan sagu (metroxylon sagu rottb). Pharmacon Jurnal Ilmiah Farmasi, 2(3), 112117.

Tonahi, J. M. M., Nuryanti, S., \& Suherman. (2014). Antioksidan dari daun sirih merah (piper crocatum). Jurnal Akademika Kimia, 3(3), 158-164.

Winarsih, H. (2007). Antioksidan alami dan radikal. Yogyakarta: Kanisius.

Yoga, I. K. W. (2015). Penentuan konsentrasi optimum kurva standar antioksidan; asam galat, asam askorbat, dan trolox ${ }^{\circledR}$ terhadap radikal bebas DPPH. Prosiding Seminar Nasional FMIPA Undiksha V, 316-321. Bali: FMIPA Undiksha.

Zuhra, C. F., Tarigan, J. B., \& Sihotang, H. (2008). Aktivitas antioksidan senyawa flavonoid dari daun katuk (sauropus androgunus (1) merr.). Jurnal Biologi Sumatera, 3(1), 7-10. 